\title{
Power quality improvement in switched mode power supplies using two stage DC-DC converter
}

\author{
Shikha Singh*, G. Bhuvaneswari and Bhim Singh \\ Department of Electrical Engineering, Indian Institute of Technology Delhi, New Delhi-110016, INDIA \\ "Corresponding Author: e-mail: Ishikha.singh@gmail.com, Tel +91-9313631999
}

\begin{abstract}
This paper deals with an improved power quality multiple output switched mode power supply (SMPS) using two stage DCDC converter. A non-isolated buck-boost DC-DC converter is used as the first stage whereas single ended primary inductance converter (SEPIC) is used in the second stage. The first stage of buck-boost converter is designed in discontinuous conduction mode (DCM) for inherent power factor (PF) correction. Design and simulations of the two stage DC-DC converter with load variations on the SMPS are performed in MATLAB software to demonstrate the effectiveness of the multiple output DC-DC converter to have a stiff voltage regulation and negligible ripple.
\end{abstract}

Keywords: DC-DC converter; Two stage; PFC; THD; Buck-boost converter; SEPIC; SMPS; Power quality.

DOI: http://dx.doi.org/10.4314/ijest.v4i1.7S

\section{Introduction}

Multiple output DC-DC converters are desirable for a variety of applications to reduce the number of power supplies, complexity, space and cost than a large number of single output converters. Now a days, a DC-DC converter consisting of two stages is becoming popular as the use of first stage eliminates the second harmonic voltage effect that is reflected at the output because of single phase AC mains input (Zhu et al, 2005; Abe et al, 2003). The first stage converter can be a non-isolated DC-DC converter and the second stage should be an isolated DC-DC converter having multiple outputs. To reduce the complexity, cost and space, only a single output (the most sensitive one) is sensed and regulated by feedback control. Generally, in the front end, a diode bridge is used to convert $\mathrm{AC}$ mains voltage to unregulated DC voltage which results in poor power factor (PF). To compensate for this, in the present work, a DC-DC converter (Pressmen, 1998; Rashid, 2004) is used with power factor correction (PFC) circuit to meet the IEEE and IEC standards (IEEE 519, 1992; IEC 61000-3-2, 2004).

A non-isolated buck-boost converter capable of stepping up/down the input DC voltage is added as the first stage for the coarse regulation of the output voltage. Non-inverting buck-boost converter in boundary conduction mode is reported in the literature (Lin et al, 2010; Boora et al, 2008). In the second stage, a single ended primary inductance converter (SEPIC) is used with multiple outputs. The SEPIC is the preferred choice among the design engineers due to its low component count, simplicity, capability to operate in buck and boost modes of operation and to yield regulated output DC voltage with a cost-effective structure. The use of only one switch and relatively simple control required are strong reasons for the choice of the SEPIC as a second stage. The analysis of an isolated SEPIC using an inductor voltage detection technique is reported in (Tanitteerapan, 2004) where the voltage conversion ratio of the SEPIC is used for the operation of the control circuit. It is a very difficult task to control the voltages of a multiple output converter with different load ratings. The control of the multiple outputs in a DC-DC converter is discussed in various research papers (Singh, 2006; Jung et al, 2008). Most of these papers describe the simulations done in MATLAB software which is a widely accepted simulation tool (MathWorks, 2009).

In view of these issues, this investigation deals with the design and control of an improved power quality switched mode power supply (SMPS) using a two stage DC-DC converter to obtain completely regulated and isolated outputs. In the proposed two-stage 
conversion process, a single phase non-isolated buck-boost converter is followed by the multiple output SEPIC that functions as the second stage. The circuit configuration, operation, analysis, and design of the proposed converter are presented for the SMPS. Finally, simulation results are presented to demonstrate the performance of the two stage DC-DC converter based SMPS during load and supply voltage variations.

\section{Circuit Configuration and Analysis}

Fig. 1 shows the circuit configuration of a SMPS using two stage DC-DC converter with second stage having multiple outputs. The AC supply is fed to a DBR (Diode Bridge Rectifier) which gives an uncontrolled DC voltage $\mathrm{V}_{\mathrm{d}}$ to the DC-DC converter. First stage is a non-isolated buck-boost converter. It consists of a switch Sw1 for on/off control, an inductor L to store and release energy, a high frequency diode $\mathrm{D}_{\mathrm{b}}$ and a filter capacitor $\mathrm{C}_{\mathrm{o}}$. When switch $\mathrm{S}_{\mathrm{w} 1}$ is $\mathrm{ON}$, the inductor $\mathrm{L}$ stores energy and the capacitor $\mathrm{C}_{\mathrm{o}}$ discharges across the load. When $\mathrm{S}_{\mathrm{w} 1}$ turns $\mathrm{OFF}$, the inductor stored energy charges the capacitor and supplies the load through the diode $D_{b}$. As the inductance polarity is reversed when it transfers energy and hence the output voltage has a reverse polarity compared to the input side. The output voltage of the non-isolated buck-boost converter is sensed and compared with reference voltage $\mathrm{V}_{\text {ref } 1}$ to generate the voltage error signal $\mathrm{V}_{\mathrm{e} 1}$. This voltage error is given to a PI (Proportional - Integral) controller to nullify the error. A PWM signal is generated by comparing the output of the PI controller with a constant frequency ramp waveform which is given to the switch $\mathrm{S}_{\mathrm{w} 1}$ to control its duty ratio and hence regulated output voltage is obtained along with automatic current shaping.

The output of the first stage is given to the isolated SEPIC DC-DC converter. The SEPIC consists of an inductor $\mathrm{L}_{1}$, a capacitor $C_{1}$, a switch $S_{w 2}$, a magnetizing inductor $L_{m}$ with primary winding $N_{p}$ and five secondary windings $N_{s 1}, N_{s 2}, N_{s 3}, N_{s 4}, N_{s 5}$ for the high frequency transformer (HFT), high frequency diodes $\mathrm{D}_{1}, \mathrm{D}_{2}, \mathrm{D}_{3}, \mathrm{D}_{4}, \mathrm{D}_{5}$ and output filter capacitors $\mathrm{C}_{\mathrm{o} 1}, \mathrm{C}_{\mathrm{o} 2}, \mathrm{C}_{\mathrm{o} 3}, \mathrm{C}_{04}, \mathrm{C}_{\mathrm{o} 5}$ respectively. A SEPIC stores the energy in an inductor, and transfers that energy to the output storage capacitor. This energy is released through the secondary windings when the switch $\mathrm{S}_{\mathrm{w} 2}$ is turned off. All the outputs are isolated from each other. One of the output voltage which is the most sensitive to the disturbances is sensed and compared with the reference voltage. The rest of the outputs are regulated by the duty cycle variation of the SEPIC which is determined by the control loop of the sensed output. The proper winding arrangements of the HFT lead to the control of all the output voltages. The voltage error $\mathrm{V}_{\mathrm{e} 2}$ (obtained from the feedback amplifier that amplifies the difference between the output voltage $\mathrm{V}_{\mathrm{o}}$ and the reference voltage $\mathrm{V}_{\text {ref2 }}$ ) is amplified in a PI controller, output of which is compared with a high frequency saw-tooth ramp, thus providing the pulses to the switch $\mathrm{S}_{\mathrm{w} 2}$. By controlling the duty ratio, the power flow is controlled in a very efficient way. .

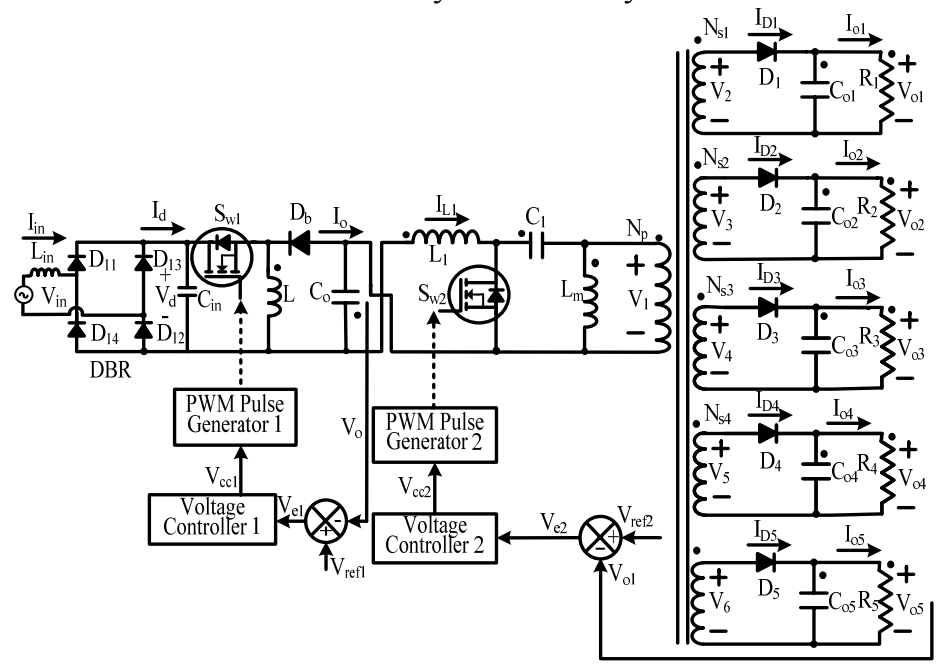

Figure1. Circuit configuration of improved power quality SMPS using two stage DC-DC converter

\section{Design of Improved Power Quality Based SMPS Using Two Stage DC-DC Converter}

In this section, the steady state analysis of the two stage DC-DC converter based SMPS is carried out to derive the required design equations for the converter. The two stage DC-DC converter can be viewed as a non-isolated DC-DC buck-boost converter cascaded with an isolated SEPIC. For the analysis, it is considered that the switches and diodes are ideal; the output filter capacitors are very large to keep the output voltage constant. The switching frequency is considered much higher than the line frequency so that average quantities in one switching cycle can be considered in place of instantaneous quantities. The HFT leakage inductance and stray capacitance are considered negligible. 
conduction mode (DCM) to avoid sensing of input current and voltage thus reducing the complexity. The voltage follower approach is used in the non-isolated buck- boost converter. When the switch $S_{w 1}$ is closed, the inductor current increases linearly; diode $\mathrm{D}_{\mathrm{b}}$ remains in OFF condition. The change in the inductor current as,

$\left(\Delta \mathrm{i}_{\mathrm{L}}\right)_{\mathrm{ON}}=\mathrm{DT}\left(\mathrm{V}_{\mathrm{d}} / \mathrm{L}\right)$

where $V_{d}$ is the input voltage of the non-isolated buck-boost converter, $D=t_{o n} / T$, $T$ being the switching period of the converter, $t_{\text {on }}$ being the $\mathrm{ON}$ time interval of $\mathrm{S}_{\mathrm{w} 1}$ and $\mathrm{V}_{\mathrm{L}}$ is the voltage across the input inductor $\mathrm{L}$.

When the switch is turned OFF and the diode $\mathrm{D}_{\mathrm{b}}$ conducts, the inductor voltage is equal to the output voltage. So, $\mathrm{V}_{\mathrm{L}}=\mathrm{V}_{\mathrm{o}}=\mathrm{L}\left(\Delta \mathrm{i}_{\mathrm{L}}\right)_{\mathrm{OFF}} /\left(\mathrm{D}_{1} \mathrm{~T}\right)$

So, the change in the inductor current during OFF period may be written as,

$\left(\Delta \mathrm{i}_{\mathrm{L}}\right)_{\mathrm{OFF}}=\mathrm{V}_{\mathrm{o}} \mathrm{D}_{1} \mathrm{~T} / \mathrm{L}$

where $\mathrm{D}_{1}$ is less than (1-D)T for DCM i.e. OFF period of $\mathrm{S}_{\mathrm{w} 1}$ during which diode $\mathrm{D}_{\mathrm{b}}$ is conducting.

The net change in the inductor current must be zero over one PWM period under steady state. Therefore, from eqns. (1) and (3),

$\left(\Delta \mathrm{i}_{\mathrm{L}}\right)_{\mathrm{ON}}+\left(\Delta \mathrm{i}_{\mathrm{L}}\right)_{\mathrm{OFF}}=0$

Substituting eqn. (1) and eqn. (3) in eqn. (4),

$\mathrm{DT}\left(\mathrm{V}_{\mathrm{d}} / \mathrm{L}\right)+\mathrm{V}_{\mathrm{o}} \mathrm{D}_{1} \mathrm{~T} / \mathrm{L}=0$

Simplifying eqn. (5),

$\mathrm{V}_{\mathrm{o}} / \mathrm{V}_{\mathrm{d}}=\mathrm{D} / \mathrm{D}_{1}$

The diode current is same as the output current during its conduction interval and hence,

$\mathrm{I}_{\mathrm{o}}=\mathrm{I}_{\mathrm{m}} \mathrm{D}_{1} \mathrm{~T} /(2 \mathrm{~T})$

Where $\mathrm{I}_{\mathrm{m}}$ is the maximum current that flows during the ON period. Therefore,

$\Delta \mathrm{i}_{\mathrm{L}}=\mathrm{I}_{\mathrm{m}}=\mathrm{V}_{\mathrm{d}} \mathrm{DT} / \mathrm{L}$

Substituting the value of $I_{m}$ in eqn. (7), the $D_{1}$ is calculated as,

$\mathrm{D}_{1}=2 \mathrm{I}_{0} \mathrm{~L} /\left(\mathrm{V}_{\mathrm{d}} \mathrm{DT}\right)$

The value of duty cycle $\mathrm{D}$ is considered as 0.645 for $\mathrm{V}_{\mathrm{d}}=0.9 * 220 \mathrm{~V}=198 \mathrm{~V}$ and $\mathrm{V}_{\mathrm{o}}=360 \mathrm{~V}$. So from eqn. (6), $\mathrm{D}_{1}$ is calculated as 0.34. So the inductor value from eqn. (1) is $1.04 \mathrm{mH}$ for $\mathrm{I}_{\mathrm{o}}=\mathrm{P}_{\mathrm{o}} / \mathrm{V}_{\mathrm{o}}=450 \mathrm{~W} / 360 \mathrm{~V}=1.25 \mathrm{~A}$ and the $\mathrm{T}=40 \mu \mathrm{s}$. The second harmonic voltage is reflected on the output capacitor because of single phase AC mains feeding the buck-boost converter. To reduce the second harmonic voltage, the output filter is designed to maintain constant voltage at DC link and desired load current in all conditions. So the average value of the output current is,

$\mathrm{I}_{\mathrm{o}}=\mathrm{V}_{\mathrm{d}} \mathrm{I}_{\mathrm{d}} / \mathrm{V}_{\mathrm{o}}$

The charging current of the output capacitor is,

$I_{c o}(t)=\left(-V_{d} I_{d} \cos 2 \omega t\right) / V_{o}=-I_{0} \cos 2 \omega t$

The output voltage $\mathrm{V}_{\mathrm{o}}$ can be calculated as,

$V_{o}=\frac{1}{C_{o}} \int I_{c} d t=-\frac{I_{o}}{2 \omega C_{o}} \sin 2 \omega t$

The output voltage has ripples equal to the amplitude of the above relation. i.e.,

$\Delta \mathrm{V}_{\mathrm{o}}=\mathrm{I}_{\mathrm{o}} /\left(2 \omega \mathrm{C}_{\mathrm{o}}\right)$

where $I_{o}$ is the output current of the non-isolated buck-boost converter, $\omega$ is equal to $2^{*} \pi^{*} \mathrm{f}$, $\mathrm{f}$ is the fundamental frequency $(50 \mathrm{~Hz})$ and $\Delta \mathrm{V}_{\mathrm{o}}$ is the ripple of the output voltage.

The ripple in the output voltage can be kept low by selecting a large value of $\mathrm{C}_{\mathrm{o}}$ which is given as,

$\mathrm{C}_{\mathrm{o}}=\mathrm{I}_{\mathrm{o}} /\left(2 \omega \Delta \mathrm{V}_{\mathrm{o}}\right)$

From eqn. (14), substituting the output current $\mathrm{I}_{\mathrm{o}}=450 \mathrm{~W} / 360 \mathrm{~V}=1.25 \mathrm{~A}, \omega=314 \mathrm{rad} / \mathrm{sec}$ and $\Delta \mathrm{V}_{\mathrm{o}}=2 \%$ of the output voltage $(7.2 \mathrm{~V})$, the value of output filter capacitor $\mathrm{C}_{\mathrm{o}}$ is obtained as $270 \mu \mathrm{F}$.

3.2 Design of SEPIC: The SEPIC is designed in continuous conduction mode to make the component values low. There is no need of sensing input current and input voltage as the output of first stage is DC voltage. In SEPIC, when the switch $\mathrm{S}_{\mathrm{w} 2}$ is ON, the inductor current changes as,

$\left(\Delta \mathrm{i}_{\mathrm{L} 1}\right)_{\mathrm{ON}}=\mathrm{V}_{\mathrm{o}} \mathrm{D}_{\mathrm{s}} \mathrm{T} / \mathrm{L}_{1}$

where $\mathrm{V}_{\mathrm{o}}$ is the input voltage of the SEPIC which is the output from the first stage, $\mathrm{D}_{\mathrm{s}}$ is the duty cycle of the SPEIC.

The change in inductor current, when switch $\mathrm{S}_{\mathrm{W} 2}$ turns $\mathrm{OFF}$, is,

$\left.\left(\Delta \mathrm{i}_{\mathrm{L} 1}\right)_{\mathrm{OFF}}=\left\{\mathrm{V}_{\mathrm{o}}-\mathrm{V}_{\mathrm{Cl}}-\mathrm{V}_{\mathrm{o} 1}\left(\mathrm{~N}_{\mathrm{p}} / \mathrm{N}_{\mathrm{s} 1}\right)\right\} / \mathrm{L}_{1}\right\}\left(1-\mathrm{D}_{\mathrm{s}}\right) \mathrm{T}$

where $\mathrm{N}_{\mathrm{p}}$ and $\mathrm{N}_{\mathrm{s} 1}$ are the number of turns of the primary winding and secondary windings of the HFT, $\mathrm{n}=\left(\mathrm{N}_{\mathrm{s} 1} / \mathrm{N}_{\mathrm{p}}\right)$ is the turns ratio of HFT, $\mathrm{V}_{\mathrm{cl}}$ is the voltage across the capacitor $\mathrm{C}_{1}$ and $\mathrm{V}_{\mathrm{ol}}$ is the output voltage of SEPIC.

Under steady state condition the change in the inductor current is zero over a period $\mathrm{T}$ as,

$\left(\Delta \mathrm{i}_{\mathrm{L} 1}\right)_{\mathrm{ON}}+\left(\Delta \mathrm{i}_{\mathrm{L} 1}\right)_{\mathrm{OFF}}=0$ 
Substituting eqn. (15) and eqn. (16) in eqn. (17),

$\left.\left.\mathrm{V}_{\mathrm{o}} \mathrm{D}_{\mathrm{s}} \mathrm{T} / \mathrm{L}_{1}+\mathrm{V}_{\mathrm{o}}-\mathrm{V}_{\mathrm{Cl}}-\mathrm{V}_{\mathrm{o} 1}\left(\mathrm{~N}_{\mathrm{p}} / \mathrm{N}_{\mathrm{s} 1}\right)\right\} / \mathrm{L}_{1}\right\}\left(1-\mathrm{D}_{\mathrm{s}}\right) \mathrm{T}=0$

On solving eqn. (18), we obtain

$\mathrm{V}_{\mathrm{o} 1} / \mathrm{V}_{\mathrm{o}}=\mathrm{nD}_{\mathrm{s}} /\left(1-\mathrm{D}_{\mathrm{s}}\right)$

From eqn. (19) it can be seen that the output voltage of the SEPIC can be varied by adjusting the duty ratio of the switch $\left(\mathrm{D}_{\mathrm{s}}\right)$ and the HFT turns ratio (n). The duty cycle is considered as 0.45 for its optimum operation, so from eqn. (19) the turns ratio ' $n$ ' is calculated as 0.0407 for $\mathrm{V}_{\mathrm{o}}=360 \mathrm{~V}, \mathrm{~V}_{\mathrm{o} 1}=12 \mathrm{~V}$.

The input inductor value $\mathrm{L}_{1}$ can be calculated for a given value of its ripple current. During the ON period the inductor current increases linearly.

$\mathrm{L}_{1}=\mathrm{V}_{\mathrm{o}} \mathrm{D}_{\mathrm{s}} /\left(\mathrm{f}_{\mathrm{s}} \Delta \mathrm{i}_{\mathrm{L} 1}\right)$

The value of the inductor $\mathrm{L}_{1}$ from eqn. (20) is computed to be $15 \mathrm{mH}$ for a ripple current of $10 \%(0.204 \mathrm{~A})$ and a switching frequency of $\mathrm{f}_{\mathrm{s}}=50 \mathrm{kHz}$.

The value of capacitor $\mathrm{C}_{1}$ for a given value of ripple voltage is, $\mathrm{C}_{1}=\mathrm{nV}_{\mathrm{o} 1} \mathrm{D}_{\mathrm{s}} /\left(\mathrm{R}_{1} \mathrm{f}_{\mathrm{s}} \Delta \mathrm{V}_{\mathrm{Cl}}\right)$

According to eqn. (21), the value of capacitor $C_{1}$ is computed as $=400 \mu \mathrm{F}$ for $\mathrm{V}_{\mathrm{ol}}=12 \mathrm{~V}, \mathrm{D}_{\mathrm{s}}=0.45, \mathrm{R}_{1}=12 \mathrm{~V} / 15 \mathrm{~A}=0.8 \Omega$ and $\mathrm{f}_{\mathrm{s}}=50$ $\mathrm{kHz}$.

The output voltage ripple $\left(\Delta \mathrm{V}_{\mathrm{ol}}\right)$ is calculated during ON period, in which output capacitor $\left(\mathrm{C}_{\mathrm{o} 1}\right)$ is discharged through load.

Thus the output voltage ripple is,

$\Delta \mathrm{V}_{\mathrm{o} 1}=\mathrm{V}_{\mathrm{o} 1} \mathrm{D}_{\mathrm{s}} \mathrm{T} /\left(\mathrm{R}_{1} \mathrm{C}_{\mathrm{o} 1}\right)$

The value of output capacitor $\left(\mathrm{C}_{\mathrm{o} 1}\right)$ can be calculated from eqn. (22) for a given ripple voltage $\left(\Delta \mathrm{V}_{\mathrm{ol}}\right)$ as,

$\mathrm{C}_{\mathrm{o} 1}=\mathrm{V}_{\mathrm{o} 1} \mathrm{D}_{\mathrm{s}} /\left(\mathrm{f}_{\mathrm{s}} \mathrm{R}_{1} \Delta \mathrm{V}_{\mathrm{o} 1}\right)$

The output filter capacitor $\mathrm{C}_{01}$ value is calculated as $560 \mu \mathrm{F}$ for $\mathrm{V}_{\mathrm{ol}}=12 \mathrm{~V}, \mathrm{D}_{\mathrm{s}}=0.45, \mathrm{R}_{1}=12 \mathrm{~V} / 15 \mathrm{~A}=0.8 \Omega, \mathrm{f}=50 \mathrm{kHz}$ and $\Delta \mathrm{V}_{\mathrm{ol}}=2 \%$ $(0.24 \mathrm{~V})$. The design equations used in the designing of the converter are based on the derivation of the output of the highest rating with the input. For rest of the outputs, the equations are derived using the HFT turns ratio. The other output voltages, components value are calculated by using the same design equations which are as follows: $\mathrm{C}_{02}=2.8 \mathrm{mF}, \mathrm{C}_{03}=4.09 \mathrm{mF}, \mathrm{C}_{04}=30 \mu \mathrm{F}, \mathrm{C}_{05}=27 \mu \mathrm{F}$ for $\mathrm{V}_{\mathrm{o} 2}=5 \mathrm{~V}, \quad \mathrm{~V}_{03}=3.3 \mathrm{~V}, \quad \mathrm{~V}_{\mathrm{o} 4}=-12 \mathrm{~V}, \quad \mathrm{~V}_{\mathrm{o} 5}=-5 \mathrm{~V}, \quad \mathrm{R}_{2}=5 \mathrm{~V} / 30 \mathrm{~A}=0.16 \Omega, \quad \mathrm{R}_{3}=3.3 \mathrm{~V} / 30 \mathrm{~A}=0.11 \Omega, \quad \mathrm{R}_{4}=-12 \mathrm{~V} / 0.8 \mathrm{~A}=15 \Omega, \quad \mathrm{R}_{5}=-$ $5 \mathrm{~V} / 0.3 \mathrm{~A}=16.66 \Omega$ and ripple in the output voltages $=2 \%$ of the respective output voltages.

\section{Control Algorithm}

The control scheme for the two stage multiple output SMPS consists of voltage controllers and the PWM pulse generators. The control for non-isolated buck-boost converter and SEPIC are given in this section.

4.1 Control for Non-isolated Buck-Boost Converter: The non-isolated buck-boost converter is designed in DCM so that extra voltage/current sensors to sense input current and voltage can be avoided. A voltage follower control approach is chosen to regulate the output voltage of the converter. Initially the control loop computes the output voltage error and then the voltage error is given to a PI voltage controller and the output of this is further given to a PWM generator to obtain the ON/OFF control pulses.

4.1.1 Voltage Controller1: It consists of a PI controller which has two gains $\mathrm{K}_{\mathrm{p} 1}$ and $\mathrm{K}_{\mathrm{I1}}$. $\mathrm{K}_{\mathrm{p} 1}$ performs the proportional action while $\mathrm{K}_{\mathrm{Il}}$ performs integral action. A PI controller gives control signal $\left(\mathrm{V}_{\mathrm{ccl}}\right)$ to reduce the voltage error. At $\mathrm{n}^{\text {th }}$ instant of time, the voltage error $V_{\mathrm{el}}(\mathrm{n})$ is calculated as,

$\mathrm{V}_{\mathrm{e} 1}(\mathrm{n})=\mathrm{V}_{\text {refl }}(\mathrm{n})-\mathrm{V}_{\mathrm{o}}(\mathrm{n})$

The controller output $\mathrm{V}_{\text {ccl }}(\mathrm{n})$ at $\mathrm{n}^{\text {th }}$ instant is given as, $\mathrm{V}_{\mathrm{ccl}}(\mathrm{n})=\mathrm{V}_{\mathrm{ccl}}(\mathrm{n}-1)+\mathrm{K}_{\mathrm{p} 1}\left\{\mathrm{~V}_{\mathrm{el} 1}(\mathrm{n})-\mathrm{V}_{\mathrm{e} 1}(\mathrm{n}-1)\right\}+\mathrm{K}_{\mathrm{Il}} \mathrm{V}_{\mathrm{el} 1}(\mathrm{n})$

4.1.2 PWM Pulse generator1: In the PWM pulse generator, the fixed high frequency saw-tooth ramp is compared with the output of PI controller $1\left(\mathrm{~V}_{\mathrm{ccl}}\right)$ to get the PWM pattern for switch $\mathrm{S}_{\mathrm{w} 1}$. When the saw tooth ramp is less than the output of the PI controller, the switch turns ON, else it is OFF.

4.2 Control for Isolated SEPIC: The control of SEPIC is carried out in continuous conduction mode (CCM) to reduce the stress of the components. Only one loop is required to regulate the output voltage as input voltage to the SEPIC is DC voltage. The control loop for SEPIC consists of only one PI voltage controller and PWM pulse generator.

4.2.1 Voltage Controller2: The PI voltage controller for SEPIC consists of two gains $\mathrm{K}_{\mathrm{p} 2}$ and $\mathrm{K}_{\mathrm{I2} . .}$ It gives the control signal $\left(\mathrm{V}_{\mathrm{cc} 2}\right)$ to reduce the voltage error i.e. the difference between actual voltage and the reference voltage $V_{\text {ref2 }}$. At $n^{\text {th }}$ instant of time, the voltage error $V_{\mathrm{e} 2}(\mathrm{n})$ is calculated as,

$\mathrm{V}_{\mathrm{e} 2}(\mathrm{n})=\mathrm{V}_{\text {ret2 } 2}(\mathrm{n})-\mathrm{V}_{\mathrm{o} 1}(\mathrm{n})$

The PI controller output $\mathrm{V}_{\mathrm{cc} 2}(\mathrm{n})$ at $\mathrm{n}^{\text {th }}$ instant is given as, 
$\mathrm{V}_{\mathrm{cc} 2}(\mathrm{n})=\mathrm{V}_{\mathrm{cc} 2}(\mathrm{n}-1)+\mathrm{K}_{\mathrm{p} 2}\left\{\mathrm{~V}_{\mathrm{e} 2}(\mathrm{n})-\mathrm{V}_{\mathrm{e} 2}(\mathrm{n}-1)\right\}+\mathrm{K}_{\mathrm{I} 2} \mathrm{~V}_{\mathrm{e} 2}(\mathrm{n})$

4.2.2 PWM Pulse Generator2: The saw-tooth ramp is compared with the output of voltage PI controller 2, $\mathrm{V}_{\mathrm{cc} 2}$ to generate the PWM signal which is given to the switch $\mathrm{S}_{\mathrm{w} 2}$ of the SEPIC.

\section{Modeling and Simulation}

The model of the two stage DC-DC converter based SMPS is developed and its performance is simulated in MATLAB environment along with Simulink and Sim Power System toolboxes to validate the proposed design. This section describes the modeling and simulation of the proposed converter. Fig. 2 shows the simulation diagram of two stage DC-DC converter. Single phase AC supply is given to diode bridge rectifier and the output of the diode bridge rectifier is connected to a non-isolated buckboost converter through a diode converter which is further fed to the second stage i.e. SEPIC. The secondary side of the HFT of SEPIC is having five outputs. One of the output which is more vulnerable to disturbance is sensed and compared with the reference voltage. The voltage error signal is given to a PI controller. The PWM generator generates the PWM signal which is given to the switch $\mathrm{S}_{\mathrm{w} 2}$. The performance of the converter is studied for variations in the load. The design parameters used for the simulation of two stage DC-DC converter is summarized in the Appendix.

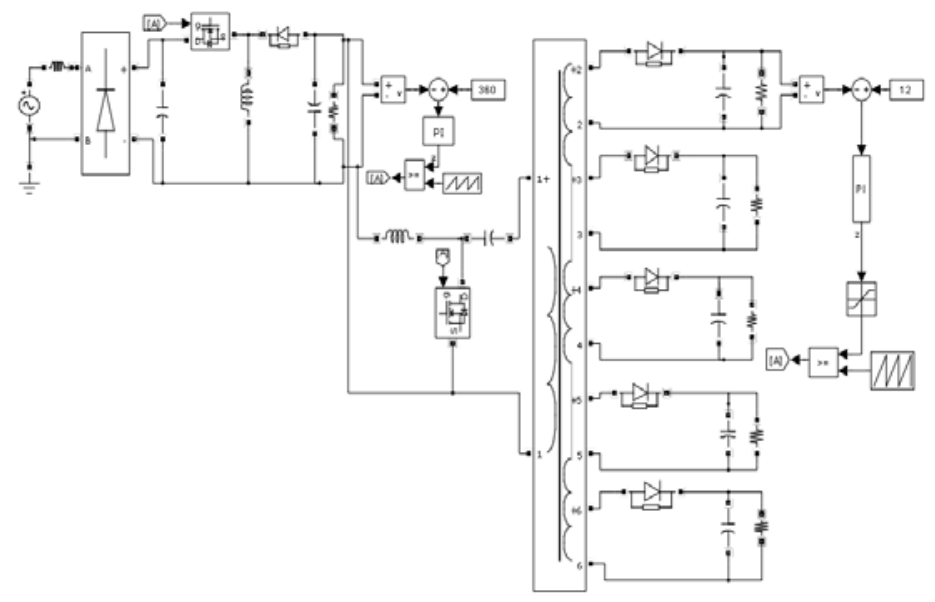

Figure 2. Simulation model of improved power quality SMPS

\section{Results and Discussion}

In this section, simulation results of an improved power quality SMPS using a two stage DC-DC converter are presented and discussed in detail. To study the performance of the SMPS and to check if various power quality indices are within specified limits, the proposed converter has been modeled, designed and simulated for the specifications given in Table I.

Simulation results of the two stage DC-DC converter based SMPS is presented to validate the design and control of the proposed configuration and to examine the various performance indices within IEEE standard 519 limit.

The simulated waveforms of the SMPS are shown in Figs. 3-10. Fig. 3 shows the supply voltage $V_{\text {in }}$, input current $I_{i n}$, output voltages $\mathrm{V}_{\mathrm{o}}, \mathrm{V}_{\mathrm{o}}, \mathrm{V}_{\mathrm{o} 2}, \mathrm{~V}_{\mathrm{o} 3}, \mathrm{~V}_{\mathrm{o} 4}, \mathrm{~V}_{\mathrm{o}}$ and output currents $\mathrm{I}_{\mathrm{o}}, \mathrm{I}_{01}, \mathrm{I}_{02}, \mathrm{I}_{03}, \mathrm{I}_{04}, \mathrm{I}_{05}$ for a two stage DC-DC converter for a $433.5 \mathrm{~W}$ SMPS at full load (100\% of load). From Fig. 3, it is clearly seen that the power factor is closed to unity as the input current follows the input voltage. Fig. 4 shows the harmonic spectrum of input mains AC current of the improved power quality SMPS using a two stage DC-DC converter at full load. The total harmonic distortion (THD) at full load is around $2.37 \%$ which is well within IEEE519 standard limit. The input current and the input voltage are in phase and the power factor is very close to unity. The input voltage of the SMPS is varied from $220 \mathrm{~V}$ to $270 \mathrm{~V}$ and from $220 \mathrm{~V}$ to $170 \mathrm{~V}$ to demonstrate the performance of the SMPS under supply voltage variations. Fig. 5 shows $\mathrm{V}_{\mathrm{in}}, \mathrm{I}_{\mathrm{in}}, \mathrm{V}_{\mathrm{o}}, \mathrm{V}_{\mathrm{o} 1} ; \mathrm{V}_{\mathrm{o} 2} ; \mathrm{V}_{\mathrm{o} 3} ; \mathrm{V}_{\mathrm{o} 4} ; \mathrm{V}_{\mathrm{o} 5}, \mathrm{I}_{\mathrm{o}}, \mathrm{I}_{\mathrm{o} 1} ; \mathrm{I}_{02} ; \mathrm{I}_{03} ; \mathrm{I}_{04} ; \mathrm{I}_{05}$ and Fig. 6 shows the harmonic spectrum of input mains AC current at $270 \mathrm{~V}$ at full load condition. From Fig. 5, it is evident that the input current and input voltage are in phase and the THD of input AC mains current is $2.8 \%$. The power factor is 0.9992 which is very close to unity. Similarly, Figs. 7 and 8 show the performance of improved power quality SMPS and harmonic spectrum of the input AC mains current respectively at $170 \mathrm{~V}$ under full load. At supply voltage of $170 \mathrm{~V}$, the current THD is slightly high and the power factor is about 0.9977 . Table II shows the various power quality indices of the improved power quality SMPS at different source voltages. To demonstrate the capability of the converter at varying loads, the load on the SMPS is varied in $+12 \mathrm{~V}$ output. Fig. 9 shows the performance of SMPS under the load variation on $12 \mathrm{~V}$ output. The load is varied from $100 \%$ to $20 \%$ and then back to $100 \%$ to reveal the dynamic performance of the converter. The power factor is found to be 0.998 at $20 \%$ load and 0.9994 at $100 \%$ load. Fig.10. shows the harmonic spectrum of the input AC mains current of SMPS at $20 \%$ load on $+12 \mathrm{~V}$ output. Table III shows the 
various power quality indices of the improved power quality SMPS at varying load conditions. It can be observed that the proposed two stage DC-DC converter based SMPS is able to deliver regulated and isolated outputs with improved power quality at the input AC mains under load and supply voltage variations.

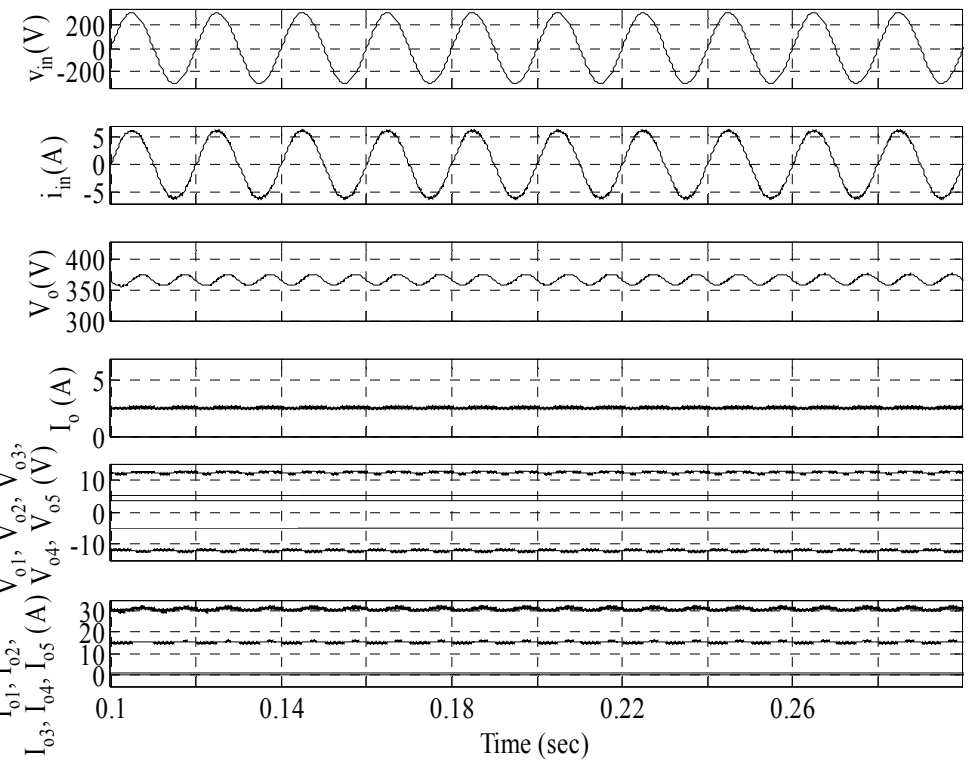

Figure 3. Input voltage, Input current, output voltages and output currents of improved power quality SMPS at $100 \%$ load
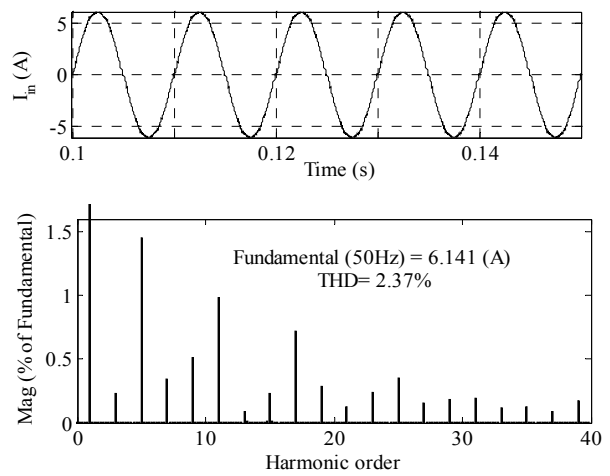

Figure 4. Input current waveform of SMPS and its harmonic spectrum at full load
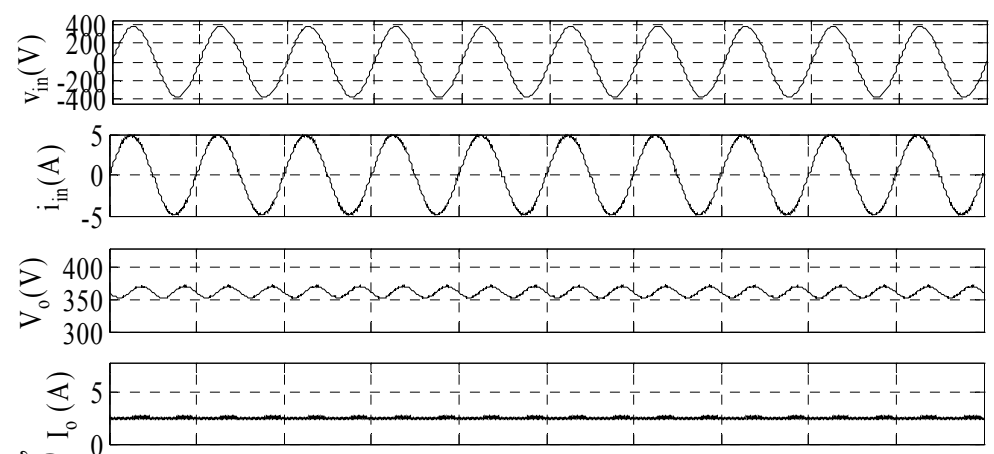

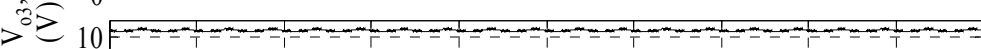

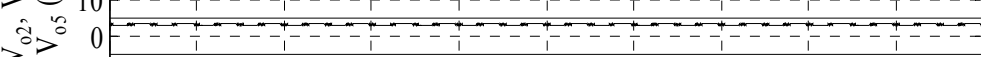

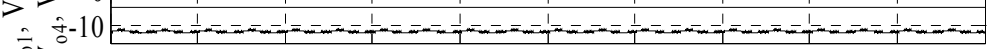

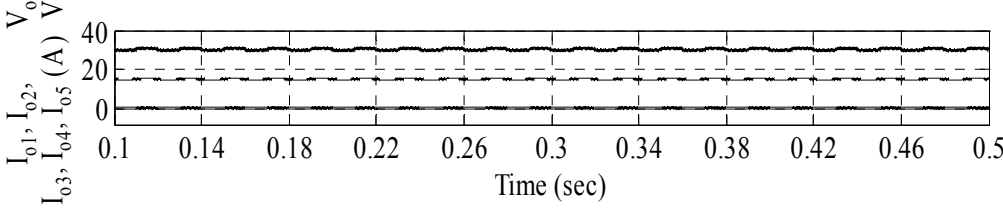


Figure 5. Input voltage, Input current, output voltages and output currents of improved power quality SMPS at 270V
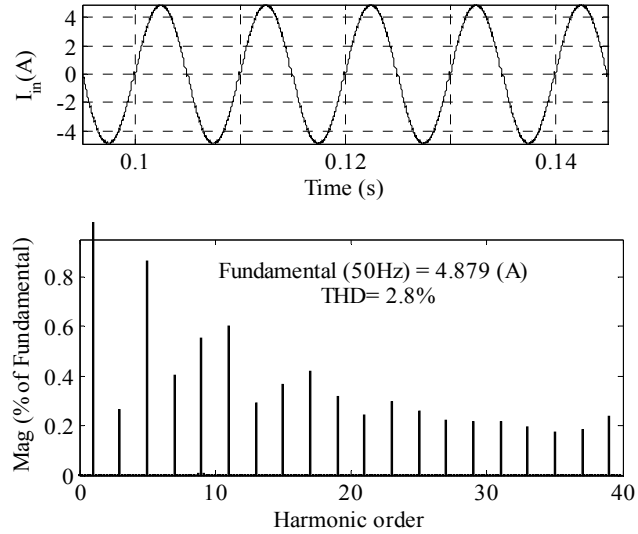

Figure 6. Input current waveform of SMPS and its harmonic spectrum at $270 \mathrm{~V}$
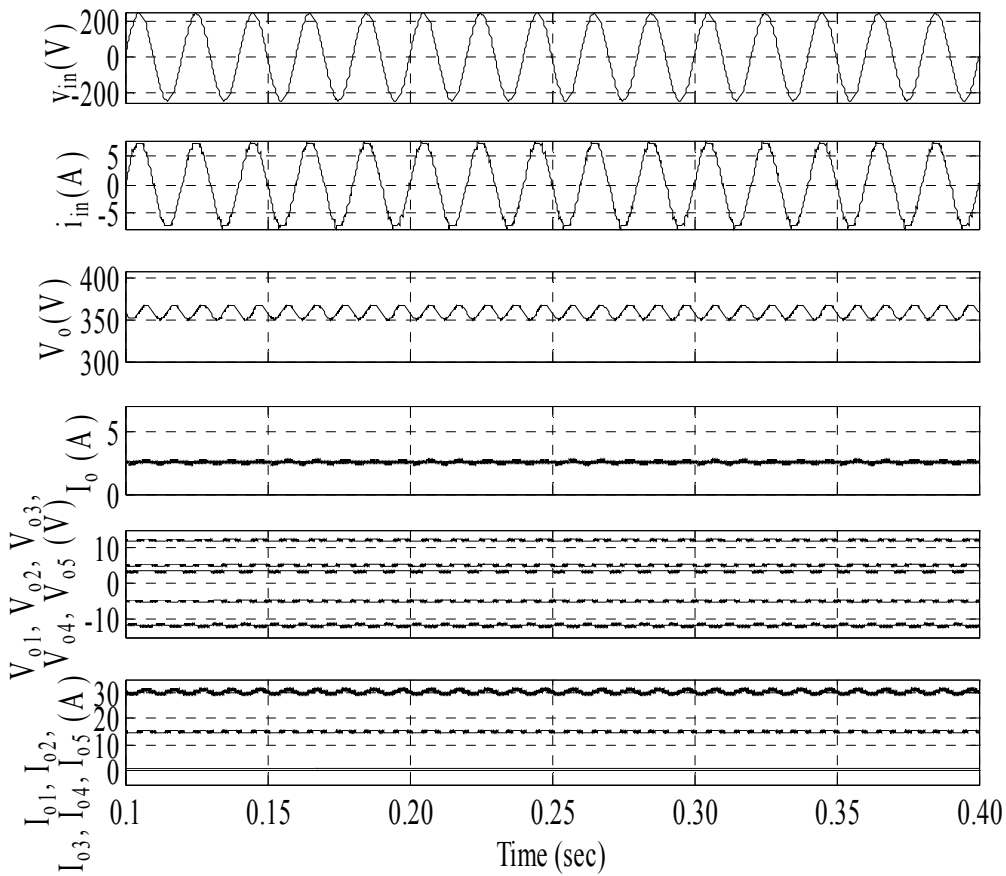

Figure 7. Input voltage, Input current, output voltages and output currents of improved power quality SMPS at 170V
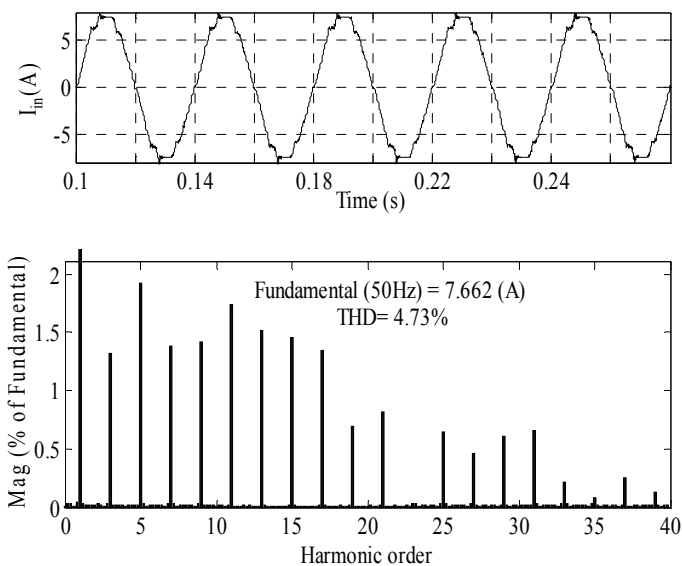

Figure 8. Input current waveform of SMPS and its harmonic spectrum at $240 \mathrm{~V}$ 

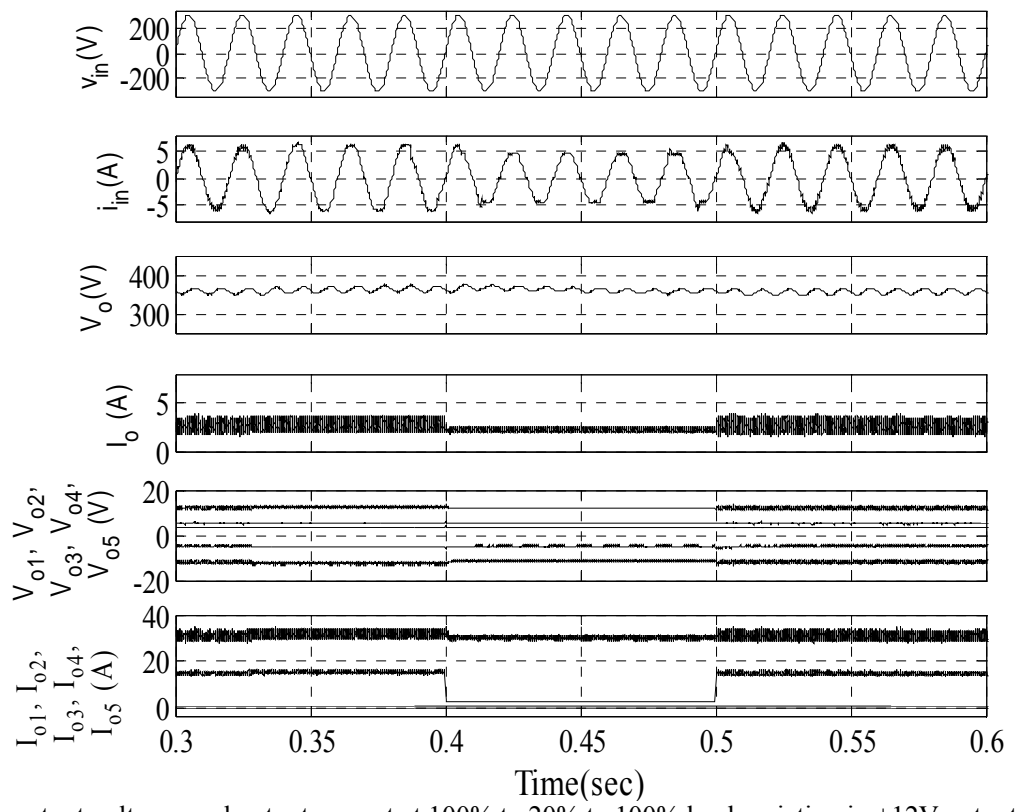

Figure 9. Input voltage, input current, output voltages and output current at $100 \%$ to $20 \%$ to $100 \%$ load variation in $+12 \mathrm{~V}$ output voltage
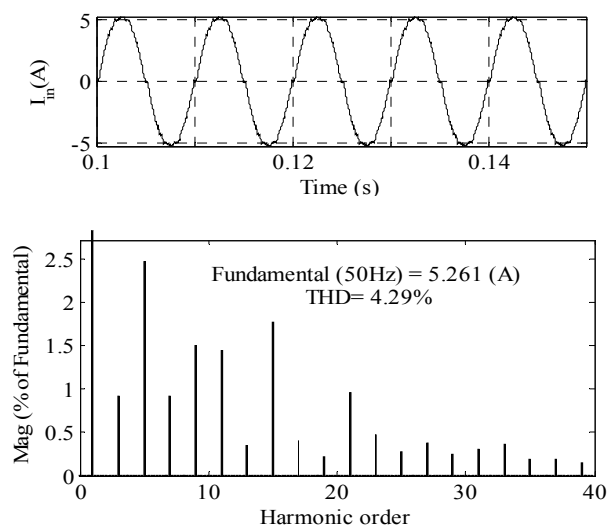

Figure 10. Input current of SMPS and its harmonic spectrum at $20 \%$ load

Table I

Improved power quality SMPS using two stage dc-dc converter specifications

\begin{tabular}{|l|l|l|}
\hline Converter & $\begin{array}{l}\text { Non-isolated } \\
\text { buck-boost }\end{array}$ & SEPIC \\
\hline Supply voltage & $220 \mathrm{~V}(\mathrm{rms})$ & $360 \mathrm{~V}$ \\
\hline \multirow{4}{*}{$\begin{array}{l}\text { Output Voltage / Output } \\
\text { Current }\end{array}$} & & $12 \mathrm{~V} / 15 \mathrm{~A}$ \\
\cline { 3 - 3 } & & $5 \mathrm{~V} / 30 \mathrm{~A}$ \\
\cline { 3 - 3 } & & $3.3 \mathrm{~V} / 30 \mathrm{~A}$ \\
\cline { 3 - 3 } & & $-5 \mathrm{~V} / 0.3 \mathrm{~A}$ \\
\cline { 3 - 3 } & & $-12 \mathrm{~V} / 0.8 \mathrm{~A}$ \\
\hline Switching Frequency & $25 \mathrm{kHz}$ & $50 \mathrm{kHz}$ \\
\hline
\end{tabular}

\section{Conclusions}

An improved power quality SMPS using a two stage DC-DC converter has been designed and modeled and its performance has been simulated under varying supply voltage and load conditions. A single phase supply has been used for feeding the two stage DC-DC converter based SMPS. A voltage follower control approach has been used in the first stage converter to provide good output voltage regulation and power factor correction whereas the second stage is chosen to be a SEPIC. The proposed SMPS is found to yield unity power factor and very low THD at the utility interface while delivering stiffly regulated and isolated outputs. The performance of the SMPS is found to be excellent even under load variations and supply voltage variations adhering to IEEE 519 standard. 
Table II

Power quality indices for the improved power quality SMPS using two stage dc-dc under varying source conditions

\begin{tabular}{|c|c|c|c|c|c|}
\hline $\begin{array}{c}\text { Input Voltage } \\
\text { (V) }\end{array}$ & $\begin{array}{c}\text { Input Current } \\
(\mathrm{A})\end{array}$ & & $\mathrm{THD}$ & $\mathrm{DF}$ & $\mathrm{PF}$ \\
\hline 170 & 5.418 & 4.73 & 0.9977 & 1 & 0.9977 \\
\hline 220 & 4.34 & 2.37 & 0.9994 & 1 & 0.9994 \\
\hline 270 & 3.45 & 2.8 & 0.9992 & 1 & 0.9992 \\
\hline
\end{tabular}

Table III

Power quality indices for the improved power quality SMPS using two stage dc-dc under varying loads conditions

\begin{tabular}{|r|r|r|r|c|}
\hline Load (\%) & $i_{\text {THD }}(\%)$ & DF & DPF & PF \\
\hline $20 \%$ & 4.29 & 0.998 & 1 & 0.998 \\
\hline $40 \%$ & 4.01 & 0.9983 & 1 & 0.9983 \\
\hline $60 \%$ & 3.89 & 0.9984 & 1 & 0.9984 \\
\hline $80 \%$ & 3.10 & 0.9990 & 1 & 0.9990 \\
\hline $100 \%$ & 2.37 & 0.9994 & 1 & 0.9994 \\
\hline
\end{tabular}

\section{Appendix}

Converter specifications: Input supply voltage: $220 \mathrm{~V}$ (rms) $311 \mathrm{~V}$ (peak), $50 \mathrm{~Hz}$;

DC output power: $433.5 \mathrm{~W}(12 \mathrm{~V} / 15 \mathrm{~A}, 5 \mathrm{~V} / 30 \mathrm{~A}, 3.3 \mathrm{~V} / 30 \mathrm{~A},-5 \mathrm{~V} / 0.3 \mathrm{~A},-12 \mathrm{~V} / 0.8 \mathrm{~A})$

Switching frequency: $25 \mathrm{kHz}$ (for buck-boost converter), $50 \mathrm{kHz}$ (for SEPIC)

$\mathrm{K}_{\mathrm{p} 1}=0.04, \mathrm{~K}_{\mathrm{I}}=3.5, \mathrm{~K}_{\mathrm{p} 2}=0.89, \mathrm{~K}_{\mathrm{I} 2}=5.5$.

\section{Acknowledgement}

Authors would like to acknowledge the Department of Science and Technology, Government of India for the research grant for the project entitled "Power Quality Improvement in Power Converter Systems" to carry out this research work.

\section{References}

Abe S., Yamamoto J., Zaitsu T. and Ninomiya T., 2003.Extension of bandwidth of two-stage dc-dc converter with lowvoltage/high-current output. Proc. of IEEE PESC, Vol. 4, pp. 1593-1598.

Boora A. A., Zare F., Ledwich G. and Ghosh A., 2008. A general approach to control a positive buck-boost converter to achieve robustness against input voltage fluctuations and load changes. Proc. of IEEE Power Electronics Specialists Conference, PESC, pp. 2011-2017.

Julian Yan Zhu and Lehman B., 2005.Control loop design for two-stage dc-dc converters with low voltage/high current output. IEEE Trans. on Power Electronics, Vol. 20, No. 1, pp. 44-55.

IEEE Recommended Practices and Requirements for Harmonics Control in Electric Power System, IEEE Standard 519, 1992.

Jung J.-H., Choi J.-M. and Kwon J.-G., 2008.Novel techniques of the reduction of standby power consumption for multiple output converters. Proc. of Twenty-Third Annual IEEE APEC’08, pp.1575-1581.

Limits for Harmonic Current Emissions, International Electro technical Commission Standard, 61000-3-2, 2004.

Lin R.-L. and Wang R.-C., 2010. Non-inverting buck-boost power-factor-correction converter with wide input-voltage-range applications. Proc. of IEEE Industrial Electronics Society IECON, pp. 599- 604.

MathWorks, Inc. Protected by U.S. patents @1984-2009.

Pressman A. I., 1998. Switching Power Supply Design. $2^{\text {nd }}$ ed. McGraw Hill, New York.

Rashid M. H., 2004. Power Electronics: Circuits, Devices and Applications. $3^{\text {rd }}$ ed. Pearson- Prentice Hall.

Singh R. K., 2006. A novel topology for multiple output dc-dc converters for one cycle control. in Proc. of IEEE PEDES '06, pp. $1-7$.

Tanitteerapan T., 2004. Analysis of power factor correction isolated sepic rectifiers using inductor detection technique. Proc. of Midwest Symposium on Circuits and Systems, Vol. 2, pp. II-321-II-324.

\section{Biographical notes}

Shikha Singh received the B. Tech. degree in electronics \& communication engineering from Uttar Pradesh Technical University, Lucknow, in 2008. She has joined as JRF in Department of Electrical Engg., IIT in 2008. She is currently working for PhD Degree at the Department of Electrical Engineering, IIT-Delhi, India. Her area of interest includes power electronics, power quality \& SMPS.

G. Bhuvaneswari is working as an Professor in the Department of Electrical Engineering, Indian Institute of Technology, New Delhi, India. She is a senior member of IEEE and a fellow of IETE, India. Her areas of Interest are Power Electronics, Electrical Machines and Drives, Power Supplies, Power Quality and HVDC Transmission. 
Bhim Singh received his B.E. in Electrical Engineering from the University of Roorkee, Roorkee, India, in 1977 and his M.Tech. and Ph.D. from the Indian Institute of Technology (IIT) Delhi, New Delhi, India, in 1979 and 1983, respectively. In 1983, he joined Department of Electrical Engineering, University of Roorkee, as a Lecturer, and in 1988 he became a Reader. In December 1990, he joined Department of Electrical Engineering, IIT Delhi, as an Assistant Professor. He became an Associate Professor in 1994 and a Professor in 1997. He has guided 38 Ph.D. dissertations, 120 M.E./M.Tech./M.S.(R) theses, and 60 BE/B.Tech. Projects. His areas of interest include power electronics, electrical machines and drives, renewable energy systems, active filters, FACTS, HVDC and power quality. Dr. Singh is a Fellow of the Indian National Academy of Engineering (INAE), the National Science Academy (NSc), the Institute of Electrical and Electronics Engineers (IEEE), the Institute of Engineering and Technology (IET), the Institution of Engineers (India) (IE(I)), and the Institution of Electronics and Telecommunication Engineers (IETE). He is also a life member of the Indian Society for Technical Education (ISTE), the System Society of India (SSI), and the National Institution of Quality and Reliability (NIQR). He received the Khosla Research Prize of the University of Roorkee in the year 1991. He was the recipient of J.C. Bose and Bimal K. Bose Awards of the Institution of Telecommunication Engineers (IETE) for his contributions in the field of power electronics in the year 2000. He was also a recipient of the Maharashtra State National Award of the Indian Society of Technical Education (ISTE) in recognition of his outstanding research work in the area of Power Quality in the year 2006. He received the PES Delhi Chapter Outstanding Engineer Award for the year 2006. He was the General Chair of the IEEE International Conference on Power Electronics, Drives and Energy Systems (PEDES'2006) and (PEDES'2010) held in New Delhi.

Received January 2012

Accepted February 2012

Final acceptance in revised form March 2012 